\title{
Perancangan Dispatch Daya Aktif Sistem Kelistrikan Sulselrabar untuk Mengatasi Pengaruh PLTB
}

\author{
Fatmawati Azis*1, Ardiaty Arief ${ }^{1}$, Muhammad Bachtiar Nappu ${ }^{1}$ \\ ${ }^{1}$ Departemen Teknik Elektro, Fakultas Teknik, Universitas Hasanuddin \\ J1. Poros Malino km. 6 Bontomarannu, Gowa, Sulawesi Selatan, 92171, Indonesia \\ *Email: fatmawati.azis90@gmail.com
}

DOI: 10.25042/jpe.052017.08

\begin{abstract}
Abstrak
Sistem kelistrikan Sulselrabar adalah sistem terinterkoneksi dari bagian Sulawesi selatan, tenggara, dan barat. Sistem ini didominasi oleh pembangkit termal dan hanya ada beberapa pembangkit hidro. Pembangkit termal ini tentunya menggunakan bahan bakar dari fosil yang merupakan sumber energi tak terbarukan yang akan berdampak pada biaya operasional yang mahal dan emisi lingkungan. Energi listrik dengan menggunakan sumber energi yang dapat diperbaharui menjadi satu-satunya solusi cerdas untuk hal ini. Pemerintah dalam programnya untuk membebaskan Indonesia dari emisi membangun kembali pembangkit listrik tenaga bayu (PLTB) di Kabupaten Sidrap Sulawesi Selatan dan PLTB Jeneponto. Tenaga angin yang digunakan PLTB memiliki kecepatan yang tidak selamanya konstan. Kemungkinan terjadinya fluktuasi kecepatan angin sangat tidak bisa dielakkan dan tidak boleh diremehkan. Hal tersebut tentunya akan mempengaruhi kestabilan sistem pada saat kedua PLTB tersebut masuk ke sistem interkoneksi. Penelitian ini dibuat untuk mengatasi permasalahan tersebut dengan merancang sistem kendali menggunakan fuzzy logic controller (FLC) untuk mempertahankan kestabilan sistem. Hasil penelitian menunjukkan bahwa FLC ini mampu mengontrol dampak perubahan kecepatan angin terhadap output PLTB dan pembangkit listrik tenaga termal (PLTT). Hasil pengontrolan FLC ketika kecepatan angin berada pada level sangat rendah $0-0.8 \mathrm{~m} / \mathrm{s}$ maka output PLTB juga berada pada level sangat rendah $0 \mathrm{~kW}$ dan output PLTT berada pada level sangat tinggi $56.000 \mathrm{~kW}$, namun sebaliknya ketika kecepatan angin berada pada level sangat tinggi 8.3-8.4 m/s maka output PLTB juga berada pada level sangat tinggi $2500 \mathrm{~kW}$ dan sebaliknya output PLTT berada pada level sangat rendah $5000 \mathrm{~kW}$.
\end{abstract}

\begin{abstract}
Development of Active Power Dispatch of Sulselrabar Electrical System in order to Overcome Effect of WPP. Sulselrabar electrical system is an interconnected system of parts of south, southeast, and west Sulawesi. The system is dominated by thermal plants and there are only a few hydro plants. These thermal plants certainly use fossil fuels that are a non-renewable energy source that will impact on operating costs and environmental emissions. Electrical energy by using renewable energy sources is the only smart solution for this problem. The Government in its program to free Indonesia from the emission is rebuilding wind power plants (WPP) in Sidrap dan Jeneponto District of South Sulawesi. Wind power used WPP has a speed that is not always constant. The possibility of wind speed fluctuations is not anavoidable and should not be underestimated. This will certainly affect the stability of the system when both WPPs join the interconnected system. This research was made to overcome these problems by designing a control system using fuzzy logic controller (FLC) to maintain system stability. The results showed that the FLC is able to control the impact of changes in wind speed on the output of WPP and termal power plants (TPP). FLC results when wind speed is at a very low level $(0-0.8 \mathrm{~m} / \mathrm{s})$ then the output of the WPP is also at a very low level $(0 \mathrm{~kW})$ and the TPP output is at a very high level $(56.000 \mathrm{~kW})$, but vice versa when wind speed is at very high level $8.3-8.4 \mathrm{~m} / \mathrm{s}$ then the output of the WPP is also at a very high level $(2500 \mathrm{~kW})$ and vice versa the TPP output is at a very low level $(5.000 \mathrm{~kW})$.
\end{abstract}

Kata-kunci: FLC, Kecepatan angin, PLTB, PLTT

\section{Pendahuluan}

Masalah energi saat ini khususnya energi listrik menjadi masalah yang diprioritaskan untuk dipikirkan keberlangsungannya dimasa yang akan datang. Energi listrik dunia saat ini sumbernya masih didominasi dari bahan bakar fosil.
Khususnya di Indonesia pembangkit listrik dengan menggunakan energi air sebagai penggerak turbin telah lama digunakan, namun ini tidak cukup untuk melayani jutaan konsumen listrik, akhirnya untuk menutupi kekurangan pasokan energi listrik pemerintah maupun swasta membangun pembangkit listrik dengan 
menggunakan bahan bakar fosil. Hal ini telah mengakibatkan banyak dampak buruk bagi lingkungan dan ekonomi [1-3]. Oleh sebab itu pemerintah, pengusaha dan generasi yang cerdas dituntut untuk memikirkan solusi-solusi cerdas apa yang harus dilakukan untuk mengatasi masalah tersebut. Energi listrik dengan menggunakan sumber energi yang dapat diperbaharui [4] menjadi satu-satunya solusi cerdas untuk hal ini.

Indonesia dianugerahi kekayaan alam yang dapat dimanfaatkan untuk menjadi sumber energi terbarukan untuk pembangkit listrik. Air, panas matahari, panas bumi dan angin mampu digunakan untuk menjadi penggerak mula dari suatu pembangkit listrik. Tercatat 3.467,95 MW untuk kapasitas pembangkit listrik tenaga air (PLTA), 8,96 MWp untuk kapasitas pembangkit listrik tenaga surya (PLTS), dan sebanyak 575 MW untuk kapasitas pembangkit listrik tenaga panas bumi (PLTPB), serta $50 \mathrm{MW}$ kapasitas pembangkit listrik tenaga angin atau bayu (PLTB) yang telah dibangun [5].

Tidak berhenti sampai pada pembangunan pembangkit listrik dengan sumber energi di atas, pemerintah dalam programnya untuk membebaskan Indonesia dari emisi. Kini telah dibangun kembali PLTB di Kabupaten Sidrap Sulawesi Selatan dengan kapasitas 70 MW [6], dan $160 \mathrm{MW}$ untuk PLTB Jeneponto [7], yang masing-masing pembangunannya dimulai tahun 2016 dan 2017, sementara potensial angin di Sulawesi Selatan ditunjukkan pada Gambar 1 [8].

Tenaga angin atau bayu yang digunakan PLTB memiliki kecepatan yang tidak selamanya konstan. Kemungkinan terjadinya fluktuasi kecepatan angin sangat tidak bisa dielakkan dan tidak boleh diremehkan. Hal tersebut tentunya akan mempengaruhi kestabilan sistem pada saat kedua PLTB tersebut masuk ke sistem interkoneksi Sulselrabar. Masalah ini menjadi buah pikiran peneliti untuk menganalisa dampak dari fluktuasi tersebut dan memikirkan solusi terbaik untuk meminimalkan dampak buruk dari fluktuasi tersebut. Penelitian ini adalah sebuah penelitian yang bertujuan untuk menganalisa kestabilan sistem ketika PLTB Sidrap dan Jeneponto masuk ke sistem interkoneksi Sulselrabar dengan mensimulasikan kestabilan sistem terhadap fluktuasi angin dan merancang sistem kendali menggunakan fuzzy logic controller (FLC) untuk mempertahankan kestabilan sistem.

\section{Metode dan pemodelan pada FLC}

Persamaan sederhana untuk menghitung aliran daya dirumuskan pada Persamaan (1). Kemudian persamaan Kron's loss terdapat pada Persamaan (3), dan Persamaan (1) dapat dirumuskan kembali pada Persamaan (2) untuk biaya pembangkitan yang lebih dari satu pembangkit. Selanjutnya total pembangkitan harus sama dengan permintaan dan losses yang terdapat pada Persamaan (4), dan inequality constraints pada Persamaan (5) [7].

$$
\begin{aligned}
& P_{L}=\sum_{i=1}^{n_{g}} \sum_{j=1}^{n_{g}} P_{i} B_{i j} P_{j} \\
& P_{L}=\sum_{i=1}^{n_{g}} \sum_{j=1}^{n_{g}} P_{i} B_{i j} P_{j}+\sum_{i=1}^{n_{g}} B_{0 i} P_{i}+B_{00} \\
& C_{i}=\sum_{i=1}^{n_{g}} \alpha_{i}+\beta_{i} P_{i}+\gamma_{i} P_{i}^{2} \\
& \sum_{i=1}^{n_{g}} P_{i}=P_{D}+P_{L} \\
& P_{i(\min )} \leq P_{i} \leq P_{i(\max )} \quad i=1, \ldots, n_{g}
\end{aligned}
$$

Melalui berbagai penurunan rumus maka akan didapatkan persamaan akhir seperti yang dituliskan pada Persamaan (6).

$$
\sum_{i=1}^{n_{g}}\left(\frac{\partial P_{i}}{\partial \lambda}\right)^{k}=\sum_{i=1}^{n_{g}} \frac{\gamma_{i} B_{i i} \beta_{i}}{2\left(\gamma_{i}+\lambda^{k} B_{i i}\right)^{2}}
$$




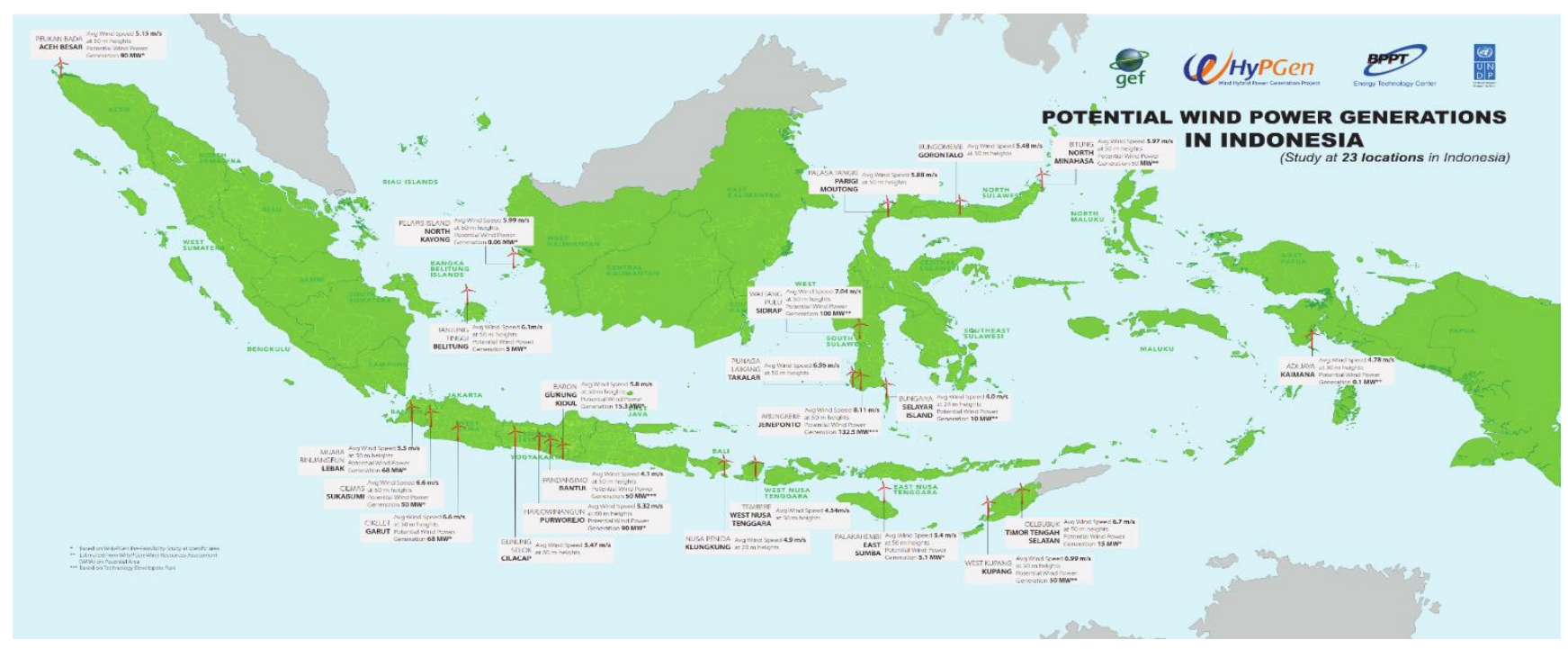

Gambar 1. Potensi angin di Indonesia [8]

Pemodelan pada FLC merupakan pemodelan rancangan energi angin yang mengontrol dua output masing-masing adalah PLTB Jeneponto 60 MW dan PLTU Jeneponto 120 MW yang memiliki satu input dan dua output. Input 1 merupakan kecepatan angin [9] mengikuti data [10] yang sementara output 1 yang pada FLC adalah daya output yang dibangkitkan oleh PLTB Jeneponto, dan output 2 merupakan output dari pembangkit yang menjadi cadangan daya ketika terjadi penurunan daya pada PLTB Jeneponto dalam penelitian ini adalah PLTU Jeneponto, masing-masing dimodelkan triangle. Data dari masing-masing input dan output disajikan pada Tabel 1, Tabel 2, dan Tabel 3. Pemodelan ini dibuat dengan mengikuti aturan-aturan (rules) yang dapat dilihat pada Tabel 4. Tabel 1, 2, 3, dan 4 untuk mempermudah mengontrol sistem agar tetap dalam kondisi stabil.

Tabel 1. Kecepatan angin yang diasumsikan

\begin{tabular}{clccc}
\hline \multirow{2}{*}{ No. } & \multicolumn{3}{c}{ Kecepatan angin yang diasumsikan } \\
\cline { 2 - 5 } Kategori & \multicolumn{3}{c}{$\mathbf{~ m} / \mathbf{s}$} \\
\hline 1 & Sangat Rendah & 0 & 0.83 & 1.66 \\
2 & Rendah & 0.83 & 1.66 & 3.32 \\
3 & Sedang & 1.66 & 3.22 & 4.98 \\
4 & Tinggi & 3.32 & 4.98 & 6.64 \\
5 & Sangat Tinggi & 4.98 & 6.64 & 8.3 \\
\hline
\end{tabular}

Tabel 2. Output daya aktif PLTB

\begin{tabular}{clccc}
\hline \multirow{2}{*}{ No. } & \multicolumn{3}{c}{ Output daya aktif PLTB } \\
\cline { 2 - 5 } & \multicolumn{1}{c}{ Kategori } & \multicolumn{3}{c}{ kW } \\
\hline 1 & Sangat Rendah & 0 & 0 & 0 \\
2 & Rendah & 0 & 0 & 150 \\
3 & Sedang & 0 & 150 & 500 \\
4 & Tinggi & 150 & 500 & 1.300 \\
5 & Sangat Tinggi & 500 & 1.300 & 2.500 \\
\hline
\end{tabular}

Tabel 3. Output daya aktif PLTT

\begin{tabular}{clccc}
\hline \multirow{2}{*}{ No. } & \multicolumn{4}{c}{ Output daya aktif PLTT } \\
\cline { 2 - 5 } Kategori & \multicolumn{3}{c}{ kW } \\
\hline 1 & Sangat Rendah & 60000 & 66000 & 72000 \\
2 & Rendah & 72000 & 78000 & 86000 \\
3 & Sedang & 86000 & 92000 & 98000 \\
4 & Tinggi & 98000 & 102000 & 108000 \\
5 & Sangat Tinggi & 108000 & 114000 & 120000 \\
\hline
\end{tabular}

Tabel 4. Aturan-aturan dalam pemodelan

\begin{tabular}{lll}
\hline \multirow{2}{*}{ Jika input } & \multicolumn{2}{c}{ Maka } \\
\cline { 2 - 3 } Sangat Rendah & Output PLTB & Output PLTT \\
Rendah & Rendah & Rendah \\
Sedang & Sedang & Sedang \\
Tinggi & Tinggi & Tinggi \\
Sangat Tinggi & Sangat Tinggi & Sangat Tinggi \\
\hline
\end{tabular}




\section{Hasil}

Hasil rancangan memperlihatkan hubungan kecepatan angin dengan output PLTB Jeneponto dan output PLTT dapat dilihat pada Tabel 4. Tabel 4 memperlihatkan nilai dari hasil rancangan aliran daya aktif berdasarkan perubahan kecepatan angin. Kecepatan angin terendah 0-0,8 $\mathrm{m} / \mathrm{s}$ dengan output aliran daya aktif PLTB 0 dan output PLTU Jeneponto 114000 kW. Kecepatan angin tertinggi $8.3-8.5 \mathrm{~m} / \mathrm{s}$ dengan output aliran daya aktif PLTB Sidrap $2.500 \mathrm{~kW}$ dan output aliran daya aktif PLTGU Sengkang $66.000 \mathrm{~kW}$. Gambar 2 dan 3 masing-masing memperlihatkan hasil dari rancangan FLC diman kecepatan angin akan mengontrol output PLTB dan kecepatan angin juga mengontrol output PLTT, sementara Gambar 4 memperlihatkan hubungan kecepatan angin dengan keduanya.

Tabel 5. Hasil perancangan menggunakan FLC

\begin{tabular}{cccc}
\hline No. & $\begin{array}{c}\text { Kecepatan } \\
\text { Angin }\end{array}$ & $\begin{array}{c}\text { Output PLTB } \\
\text { Jeneponto }\end{array}$ & $\begin{array}{c}\text { Output } \\
\text { PLTT }\end{array}$ \\
& $(\mathbf{m} / \mathbf{s})$ & $(\mathbf{k W})$ & $\mathbf{( k W )}$ \\
\hline 1 & $0-0.8$ & 0 & 114000 \\
2 & 0.9 & 31.3 & 113000 \\
3 & 1 & 50.7 & 111000 \\
4 & 1.1 & 63.3 & 109000 \\
5 & 1.2 & 69.1 & 108000 \\
6 & 1.3 & 68.9 & 108000 \\
7 & 1.4 & 64.2 & 106000 \\
8 & 1.5 & 60.6 & 105000 \\
9 & 1.6 & 57.8 & 103000 \\
10 & 1.7 & 69.6 & 102000 \\
11 & 1.8 & 99.7 & 101000 \\
12 & 1.9 & 126 & 99700 \\
13 & 2 & 143 & 98900 \\
14 & 2.1 & 158 & 98200 \\
15 & 2.2 & 171 & 97500 \\
16 & 2.3 & 181 & 96800 \\
17 & 2.4 & 189 & 96400 \\
18 & 2.5 & 196 & 96000 \\
19 & 2.6 & 201 & 95600 \\
20 & 2.7 & 204 & 95100 \\
21 & 2.8 & 207 & 94400 \\
22 & 2.9 & 209 & 93700 \\
\hline & & & \\
\hline & & 1800
\end{tabular}

\begin{tabular}{|c|c|c|c|}
\hline No. & $\begin{array}{c}\text { Kecepatan } \\
\text { Angin } \\
(\mathbf{m} / \mathbf{s})\end{array}$ & $\begin{array}{c}\text { Output PLTB } \\
\text { Jeneponto } \\
(\mathbf{k W})\end{array}$ & 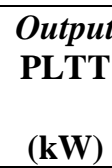 \\
\hline 23 & 3 & 211 & 92900 \\
\hline 24 & 3.1 & 213 & 92200 \\
\hline 25 & 3.2 & 214 & 91300 \\
\hline 26 & 3.3 & 216 & 90200 \\
\hline 27 & 3.4 & 350 & 89100 \\
\hline 28 & 3.5 & 459 & 88200 \\
\hline 29 & 3.6 & 531 & 87400 \\
\hline 30 & 3.7 & 580 & 86600 \\
\hline 31 & 3.8 & 616 & 85900 \\
\hline 32 & 3.9 & 643 & 85200 \\
\hline 33 & 4 & 666 & 84600 \\
\hline 34 & 4.1 & 686 & 84200 \\
\hline 35 & 4.2 & 702 & 83800 \\
\hline 36 & 4.3 & 717 & 83400 \\
\hline 37 & 4.4 & 732 & 82800 \\
\hline 38 & 4.5 & 748 & 82100 \\
\hline 39 & 4.6 & 763 & 81400 \\
\hline 40 & 4.7 & 777 & 80600 \\
\hline 41 & 4.8 & 791 & 79800 \\
\hline 42 & 4.9 & 805 & 78900 \\
\hline 43 & 5 & 837 & 77800 \\
\hline 44 & 5.1 & 932 & 76700 \\
\hline 45 & 5.2 & 1010 & 75800 \\
\hline 46 & 5.3 & 1080 & 75100 \\
\hline 47 & 5.4 & 1150 & 74300 \\
\hline 48 & 5.5 & 1200 & 73600 \\
\hline 49 & 5.6 & 1250 & 72900 \\
\hline 50 & 5.7 & 1300 & 72400 \\
\hline 51 & 5.8 & 1350 & 72000 \\
\hline 52 & 5.9 & 1390 & 71600 \\
\hline 53 & 6 & 1440 & 71200 \\
\hline 54 & 6.1 & 1490 & 70500 \\
\hline 55 & 6.2 & 1540 & 69800 \\
\hline 56 & 6.3 & 1600 & 69100 \\
\hline 57 & 6.4 & 1670 & 68300 \\
\hline 58 & 6.5 & 1760 & 67500 \\
\hline 59 & 6.6 & 1860 & 66500 \\
\hline 60 & 6.7 & 1900 & 66000 \\
\hline 61 & 6.8 & 1900 & 66000 \\
\hline
\end{tabular}




\begin{tabular}{cccc}
\hline No. & $\begin{array}{c}\text { Kecepatan } \\
\text { Angin }\end{array}$ & $\begin{array}{c}\text { Output PLTB } \\
\text { Jeneponto }\end{array}$ & $\begin{array}{c}\text { Output } \\
\text { PLTT }\end{array}$ \\
\hline 62 & $(\mathbf{m} / \mathbf{s})$ & $(\mathbf{k W})$ & $(\mathbf{k W})$ \\
63 & 6.9 & 1900 & 66000 \\
64 & 7 & 1900 & 66000 \\
65 & 7.1 & 1900 & 66000 \\
66 & 7.3 & 1900 & 66000 \\
67 & 7.4 & 1900 & 66000 \\
68 & 7.5 & 1900 & 66000 \\
69 & 7.6 & 1900 & 66000 \\
70 & 7.7 & 1900 & 66000 \\
71 & 7.8 & 1900 & 66000 \\
72 & 7.9 & 1900 & 66000 \\
73 & 8 & 1900 & 66000 \\
74 & 8.1 & 1900 & 66000 \\
75 & 8.2 & 1900 & 66000 \\
76 & 8.3 & 2500 & 66000 \\
77 & 8.4 & 2500 & 66000 \\
78 & 8.5 & 2500 & 66000 \\
\hline
\end{tabular}

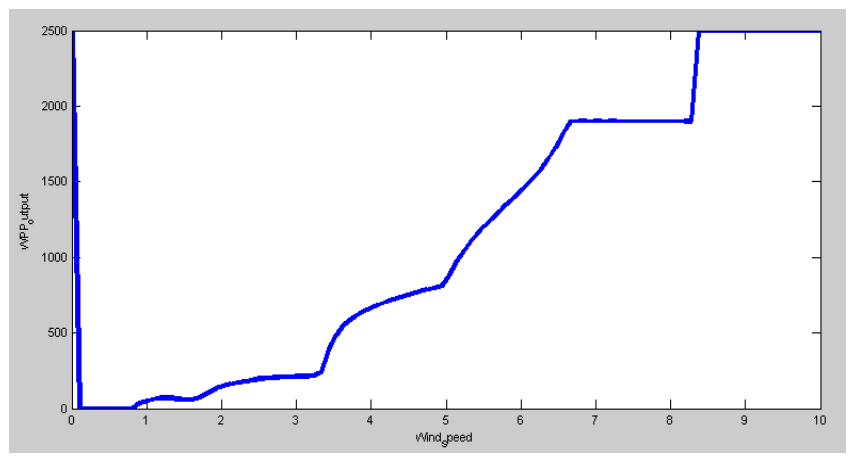

Gambar 2. Hasil perancangan FLC dimana kecepatan angin mengontrol output PLTB

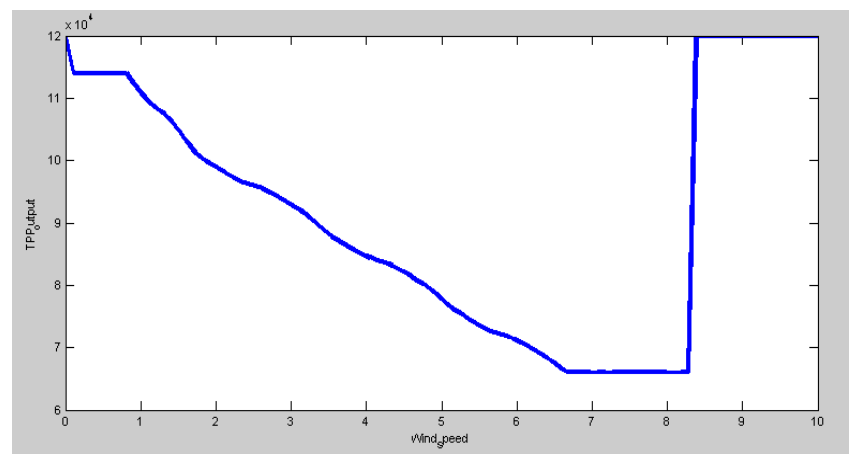

Gambar 3. Hasil perancangan FLC dimana kecepatan angin mengontrol output PLTT

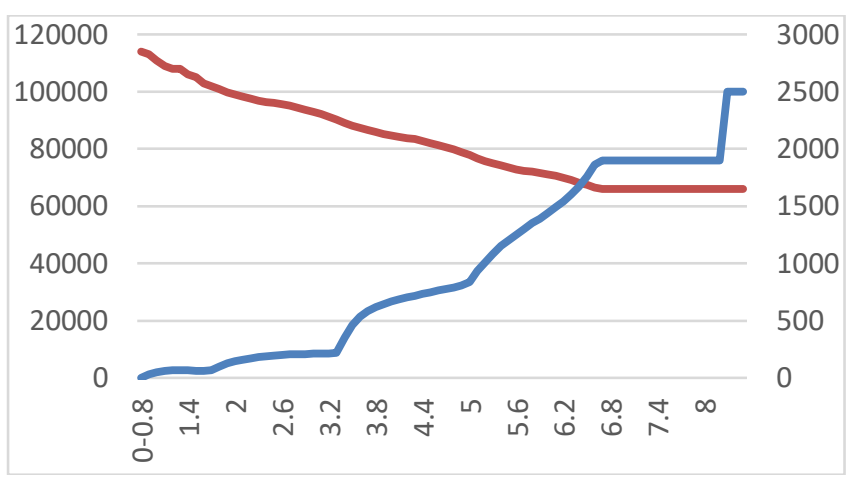

Gambar 4. Hubungan antara kecepatan angin dan kedua output.

\section{Kesimpulan}

Hasil penelitian memberikan kesimpulan:

1. Sistem interkoneksi dalam hal ini sistem kelistrikan Sulselrabar tetap stabil dengan bergabungnya PLTB dengan kondisi kecepatan angin yang stabil rata-rata $8.3 \mathrm{~m} / \mathrm{s}$.

2. Rancangan mengontrol daya aktif PLTB dan PLTT dengan kondisi kecepatan berubahubah dapat menjadi acuan untuk pengontrolan system nantinya.

\section{Daftar Pustaka}

[1] K. Siraj, H. Siraj and M. Nasir, "Modelling and Control of a Doubly Fed Induction Generator for Grid Integrated Wind Turbine," in Power Electronics and Motion Control Conference and Exposition (PEMC), 2014 16th International, 2014.

[2] A. Abdelaziz, E. Ali and S. A. Elazim, "Combined Economic and Emission Dispatch Solution Using Flower Pollination Algorithm," Electrical Power and Energy Systems, vol. 80, pp. 264-274, 201.

[3] M. B. Nappu and A. Arief, "Economic Redispatch Considering Transmission Congestion for Optimal Energy Price in a Deregulated Power System," in International Conference on Electrical Engineering and Informatics (ICEEI 2015), Denpasar-Bali, 2015.

[4] R. Shaha, D. D. Kothari and D. V. Chandrakar, "Optimization of RenawableEnergy Sources for Hybrid Power Generation," in 2016 Biennial International Conferences on Power and Energy Systems: Toward Sustainable Energy (PESTSE), 2016.

[5] ESDM, "www.djk.esdm.go.id.statistik," edisi no.28, 2015. [Online]. [Accessed 29 September 2016].

[6] PLN, "Pembangkit Listrik Tenaga Angin $70 \mathrm{MW}$ Segera Dibangun Di Sidrap", PLN, 7 April 2015. [Online]. Available: http://www.pln.co.id. [Accessed 29 September 2016].

[7] P. K. Jeneponto, "Pembangkit Listrik Tenaga Angin Segera Hadir Di Jeneponto", Kabupaten Jeneponto, 29 Juni 2015. [Online]. Available: 
www.jenepontokab.go.id. [Accessed 10 Oktober 2016].

[8] Wind Hybrid Power Generation Marketing Development Initiiative (WhyPGen), "Map of Potential Locations for Wind Power Generation in Indonesia and Pre-Feasibility Studies in 10 Locations Based on Wind Resources Assessment", [Online]. Available: http://whypgen-bppt.com/id/. [Accessed 4 June 2017].

[9] H. Saadat, "Economic Dispatch Including Losses," in Power System Analysis, New York, The McGRaw-
Hill Companies, 1999, p. 279.

[10] ENO Energy, "Leistungskurve ENO 126 | $35 \mathrm{MW}$, [Online]. Available: http://www.eno-energy.com. 